\title{
Respostas de pupunheiras (Bactris gasipaes Kunth) jovens ao alagamento(1)
}

\author{
Cláudio José Reis de Carvalho(2) e Françoise Yoko Ishida ${ }^{(3)}$
}

\begin{abstract}
Resumo - O objetivo deste trabalho foi estudar os efeitos do encharcamento do solo sobre a condutância estomática, o conteúdo relativo de água, o teor de clorofila e a concentração de N, P, K e de açúcares solúveis nos tecidos das folhas, bulbos e raízes de pupunheiras (Bactris gasipaes Kunth) jovens. Plantas com seis meses de idade foram submetidas ao alagamento das raízes por períodos contínuos de sete, 14 e 21 dias. $\mathrm{O}$ alagamento induziu o fechamento dos estômatos, apesar de os tecidos das folhas terem mantido conteúdos relativos de água em torno de $90 \%$. O alagamento provocou a redução dos teores de clorofila total, $\mathrm{N}$ orgânico, $\mathrm{P}$ e principalmente $\mathrm{K}$ nos tecidos foliares e redução significativa da biomassa das raízes. A anoxia do sistema radicular induziu o acúmulo de açúcares solúveis nos tecidos de folhas e, principalmente, de bulbos e raízes. Apesar de não ter sido detectada morte de nenhuma planta até o final do período experimental, este conjunto de alterações metabólicas permite afirmar que a pupunheira é sensível ao alagamento das raízes.
\end{abstract}

Termos para indexação: estômato, clorofila, teor de nutrientes, anoxia.

\section{Responses of young pijuayo plants (Bactris gasipaes Kunth) to flooding}

\begin{abstract}
The objective of this work was to study the effects of waterlogged soil on the stomatal conductance, the relative water content, the chlorophyll content and on the N, P, K and soluble sugar concentrations of leaf, bulb and root tissues of young pijuayo palms (Bactris gasipaes Kunth). Six month old age plants were submitted to flooding by continuous periods of seven, 14 and 21 days. Flooding induced the closure of the stomata, although the leaf tissues have maintained high relative water contents (about 90\%). Root anoxia also induced reduction of the contents of total chlorophyll, organic N, P and mainly $\mathrm{K}$ in leaf tissues and significant reduction of the root biomass. In the flooded plants, the soluble sugar contents of the leaves, bulb and roots were higher than in the same tissues of the control plants. Although no death of plants have been detected to the end of the experimental period, these metabolic alterations allow to affirm that this species (Bactris gasipaes Kunth) is sensitive to the root flooding.
\end{abstract}

Index terms: stomata, chlorophylls, nutrient content, waterlogging.

\section{Introdução}

A pupunheira (Bactris gasipaes Kunth, Arecaceae) é uma palmeira que pode ser encontrada em formações espontâneas ou semi-espontâneas na Amazônia (principalmente ao longo do rio Amazonas) e na América Central, particularmente na Costa

\footnotetext{
(1) Aceito para publicação em 19 de fevereiro de 2002 .

(2) Embrapa-Centro de Pesquisa Agroflorestal da Amazônia Oriental, Caixa Postal 48, CEP 66095-100 Belém, PA. E-mail: carvalho@cpatu.embrapa.br

(3) Instituto de Pesquisa Ambiental da Amazônia, Av. Nazaré, 669, CEP 66035-170 Belém, PA. E-mail: yoko@amazon.com.br
}

Rica, Trinidad e Tobago, Honduras, Nicarágua, Panamá. Seus frutos, estipes e folhas já eram utilizados desde muito tempo, por povos de cultura pré-colombiana. Atualmente, esta espécie está se tornando uma importante fonte de palmito industrializado, em face da redução da exploração da palmiteira tradicional (Euterpe edulis) no Centro-Oeste e do açaizeiro (Euterpe oleracea) no Norte do Brasil.

Embora na sua área de ocorrência natural esta espécie seja encontrada sob regimes pluviométricos que vão desde 1.500 a $6.000 \mathrm{~mm}$ por ano, e cultivada com sucesso em regiões com pluviosidade média de $1.700 \mathrm{a} 4.000 \mathrm{~mm}$ por ano, é fato conhecido que esta palmeira não suporta solos mal drenados ou com lençol freático alto (Villachica et al., 1996). Estas con- 
dições levam a um retardo no crescimento, clorose nas folhas e mesmo morte de plantas jovens e adultas.

Os sintomas observados em pupunheiras vegetando em solos periodicamente encharcados são reações típicas de plantas não-tolerantes ao ambiente anóxico nas raízes. Embora muito bem conhecidos na literatura sobre outras espécies (Kozlowski \& Pallardy, 1984; Pezeshki, 1994; Pezeshki et al., 1996; Kozlowski, 1997), não existem resultados experimentais avaliando os efeitos negativos da hipoxia das raízes causada pelo encharcamento do solo, sobre o crescimento e nutrição mineral da pupunheira.

No processo de domesticação, o estabelecimento de técnicas eficientes para produção de mudas é de fundamental importância. Normalmente, são necessários estudos que visem maximizar o crescimento inicial, principalmente em relação à exploração de palmito, que depende fundamentalmente do crescimento vegetativo, o qual pode ser afetado pelo estresse de carência de oxigênio nas raízes.

O objetivo deste trabalho foi avaliar os efeitos do encharcamento do solo sobre a condutância estomática, o conteúdo relativo de água, o teor de clorofila e a concentração de N, P, K e de açúcares solúveis dos tecidos de pupunheiras jovens.

\section{Material e Métodos}

Mudas de pupunheira (variedade com espinhos) foram cultivadas por seis meses em sacos de plástico com capacidade de $800 \mathrm{~cm}^{3}$, contendo uma mistura de terriço, esterco curtido e areia lavada (3:1:1), e mantidas em instalação coberta com tela "Sombrite" (50\% de interceptação da radiação incidente).

Durante o período experimental, as mudas receberam aplicações semanais de uma formulação comercial (20\% de $\mathrm{N}$ total; $10 \%$ de $\mathrm{P}_{2} \mathrm{O}_{5}$ solúvel em água; $10 \%$ de $\mathrm{K}_{2} \mathrm{O}$ solúvel em água; $0,06 \%$ de $\mathrm{Mg} ; 0,14 \%$ de $\mathrm{B} ; 1,50 \%$ de $\mathrm{Zn}$; $0,08 \%$ de $\mathrm{Mn})$ solubilizada em água destilada $\left(2 \mathrm{~g} \mathrm{~L}^{-1} \mathrm{de}\right.$ água destilada), na quantidade de $10 \mathrm{~mL}$ por planta.

O delineamento experimental foi o de blocos ao acaso, com quatro repetições. Metade das mudas foram colocadas em recipientes plásticos individuais pouco maiores do que os sacos de plástico usados para seu cultivo. A seguir, o solo foi saturado com água até a superfície, procurando não submergir o bulbo. As plantas restantes foram irrigadas diariamente, e o teor de água do solo foi mantido na condição de capacidade de campo estabelecida em ensaio pré- vio. As avaliações foram feitas aos sete, 14 e 21 dias após a aplicação dos tratamentos.

A condutância estomática $\left(\mathrm{g}_{\mathrm{s}}\right)$ foi medida nos horários das 9 às $10 \mathrm{~h}$ e das 13 às 14h, com um Porômetro Dinâmico modelo AP4 (Delta T Devices, Cambridge, U.K.). O conteúdo relativo de água foi avaliado nas mesmas folhas usadas para a mensuração da condutância estomática, usandose seis discos de $1 \mathrm{~cm}$ de diâmetro (Weatherley, 1950). Outros seis discos foram retirados das mesmas folhas, os quais foram postos em acetona a $80 \%(\mathrm{v} / \mathrm{v})$, e usados para a determinação do teor de clorofila (Arnon, 1949).

Ao final de cada período de avaliação, as plantas foram separadas em folhas, bulbo e raízes, e após lavadas, foram secadas em estufa com ventilação forçada a $80^{\circ} \mathrm{C}$, por 72 horas. Após a secagem, cada componente foi pesado e moído em moinho de facas.

Nas determinações dos teores de $\mathrm{N}$ orgânico, $\mathrm{P}$ e K nas folhas, foram pesadas amostras de $0,100 \mathrm{~g}$ de tecido moído, as quais foram digeridas em uma mistura de $3 \mathrm{~mL}$ de $\mathrm{H}_{2} \mathrm{SO}_{4}$ e $0,5 \mathrm{~mL}$ de $\mathrm{H}_{2} \mathrm{O}_{2}$ a $370^{\circ} \mathrm{C}$. As amostras digeridas foram diluídas até um volume de $100 \mathrm{~mL}$ e usadas para as análises posteriores.

$\mathrm{O} N$ orgânico foi determinado pela reação com nitroprussiato de sódio, em meio alcalino, segundo método adaptado de Solorzano (1969); o P, pela reação em meio ácido com ácido ascórbico e molibdato de amônio (Chen Junior et al., 1956), e o K, por fotometria de chama.

Os açúcares solúveis totais foram extraídos de amostras de aproximadamente $0,100 \mathrm{~g}$ dos tecidos das folhas, bulbos e raízes. Os açúcares solúveis foram obtidos após duas extrações com $8 \mathrm{~mL}$ de etanol a $70 \%$ a $70^{\circ} \mathrm{C}$, por 20 minutos, e uma lavagem com $3 \mathrm{~mL}$ de água destilada, intercalados com centrifugações a $1.000 \mathrm{~g}$ durante 15 minutos (McCready et al., 1950). Os extratos obtidos foram submetidos à evaporação em banho-maria a $80^{\circ} \mathrm{C}$, e os resíduos dissolvidos em $5 \mathrm{~mL}$ de água. Em seguida, foram adicionados 2,5 $\mathrm{mL}$ de $\mathrm{Ba}(\mathrm{OH})_{2}$ saturada, deixando-se em repouso por 15 minutos, e 2,5 $\mathrm{mL}_{\text {de }} \mathrm{ZnSO}_{4}$ a $5 \%$ (BolleJones, 1968). A seguir, as amostras foram centrifugadas a $1.000 \mathrm{~g}$ por 15 minutos, e o sobrenadante foi utilizado para quantificação dos açúcares solúveis com o reativo de Antrona (Ashwell, 1957).

Os resultados foram submetidos à análise de variância, pelo programa Systat versão 7.01, e as médias comparadas pelo teste de Tukey a $5 \%$ de probabilidade.

\section{Resultados e Discussão}

Um dos primeiros sintomas do alagamento em plantas não-tolerantes ao ambiente anóxico nas raízes é o fechamento estomático (Kozlowski \& Pallardy, 
1984; Pezeshki, 1994; Pezeshki et al., 1996; Kozlowski, 1997). O alagamento induziu uma redução significativa na condutância estomática, que mostrou uma tendência a acentuar-se com o tempo de tratamento, não levando, porém, a um fechamento completo dos estômatos, mesmo no período da tarde, o qual apresenta normalmente maior demanda evapotranspiratória (Figura 1). Em geral, sob efeito do alagamento, ocorre a diminuição da absorção de água, tanto pela redução do comprimento e superfície total das raízes, como consequiência da sua morte, como pelo aumento da resistência ao fluxo de água (Kozlowski, 1997). Estes fenômenos fazem com que plantas submetidas ao alagamento estejam sujeitas ao murchamento das folhas, caso não possuam bom controle estomático e baixa transpiração cuticular.

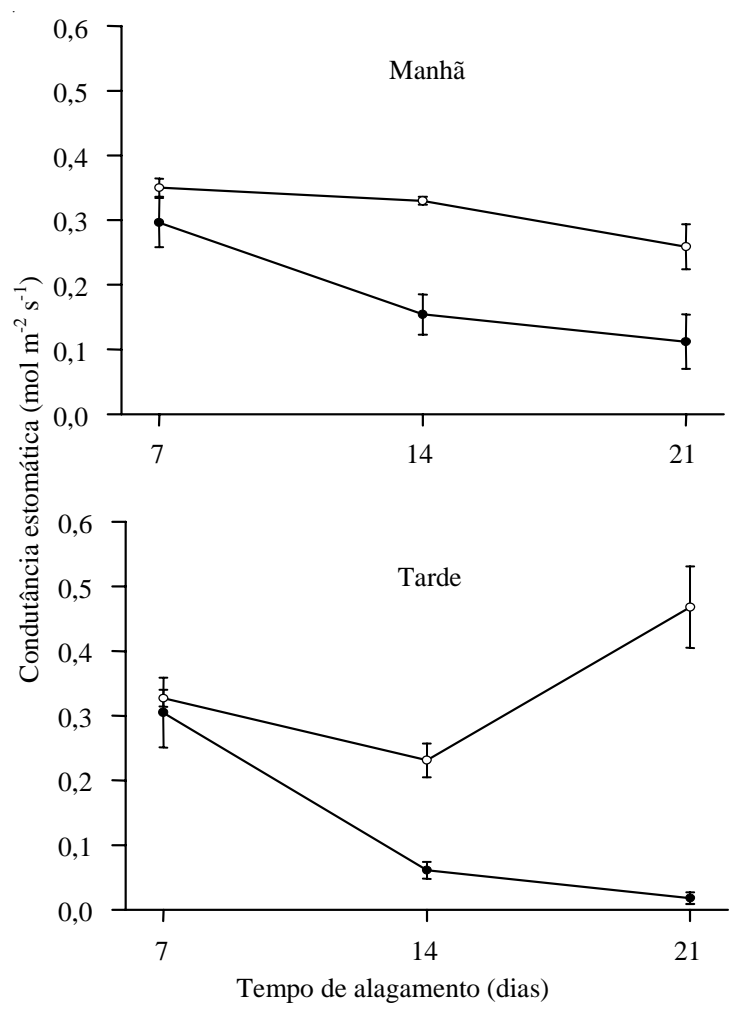

Figura 1. Condutância estomática na face abaxial das folhas de plantas alagadas (•) e não-alagadas $(\mathbf{0})$ de pupunheira nos períodos da manhã (9 às 10h) e da tarde (13 às 14h). As barras de erro representam o erro-padrão da média $(n=4)$.
Durante todo o período experimental, e no horário de maior demanda evaporativa (15h), não foram constatadas diferenças significativas entre os tratamentos $\left(F_{2,15}=0,705 ; \mathrm{P}=0,510\right)$ em relação ao conteúdo de água foliar. O conteúdo de água nos tecidos foliares das plantas não-alagadas manteve-se consistentemente próximo aos valores encontrados nas plantas sob alagamento (Tabela 1). Este fato mostra que a redução da condutância foi causada pelo fechamento dos estômatos, provocado por alterações metabólicas geradas em virtude da anoxia das raízes.

O teor de clorofila nas folhas das plantas alagadas foi inferior ao das plantas-testemunha $\left(\mathrm{F}_{1,15}=5,987\right.$; $\mathrm{P}=0,027)$, mesmo a partir do sétimo dia de tratamento (Figura 2), embora não tenham sido detectadas diferenças estatisticamente significativas com relação à interação tempo $x$ tratamento $\left(F_{2,15}=0,214\right.$; $\mathrm{P}=0,810$ ). A clorose provocada pelo encharcamento das raízes da pupunheira é um dos sinais mais freqüentemente citados nas observações empíricas. Este distúrbio, também observado em outras espécies, pode ser atribuído a vários fatores, tais como o acúmulo de substâncias tóxicas, disfunção hormonal levando à senescência, ou mesmo carência de nutrientes (Kozlowski \& Pallardy, 1984; Pezeshki, 1994; Pezeshki et al., 1996; Kozlowski, 1997). Em condições naturais, a alternância de períodos de anoxia e arejamento do solo é muito comum em terrenos com drenagem deficiente. Por este motivo, a degradação de pigmentos pode ser agravada por aumento da concentração de radicais livres (Drew, 1997), o que explicaria a intensa clorose observada nas palmeiras, quando submetidas a estas situações no campo. No presente caso, mesmo após 21 dias sob condição de encharcamento do solo, não foi notada situação de

Tabela 1. Conteúdo relativo de água (\%) de folhas de plantas alagadas e não-alagadas de pupunheira medido às $15 \mathrm{~h}^{(1)}$.

\begin{tabular}{ccc}
\hline $\begin{array}{c}\text { Tempo de } \\
\text { alagamento (dias) }\end{array}$ & Alagadas & Não-alagadas \\
\hline 7 & $89,86 \pm 1,61$ & $91,40 \pm 1,08$ \\
14 & $90,85 \pm 2,36$ & $86,86 \pm 3,05$ \\
21 & $87,29 \pm 1,71$ & $86,45 \pm 2,80$ \\
\hline
\end{tabular}

(1)Os dados representam médias de 4 repetições. 
clorose visualmente detectável. Assim, é provável que na pupunheira, os efeitos de clorose mais marcantes, ocorram no período pós-anóxico.

Nos tecidos foliares das plantas alagadas, os teores de $\mathrm{N}$ orgânico, $\mathrm{P}$ e $\mathrm{K}$ foram inferiores aos observados nas plantas não-alagadas (Tabela 2). Em espécies não-tolerantes, geralmente a redução nos teores foliares de N, P e K, provocada pela anoxia das raízes, coincide com o surgimento de clorose (Drew \& Sisworo, 1979; Drew, 1991) normalmente atribuída à deficiência de N. No presente caso, foram detectadas diferenças altamente significativas $\left(F_{1,15}=46,514 ; \mathrm{P}<0,001\right)$ entre os teores de N orgânico foliar das plantas alagadas e não-alagadas, e, embora não tenha sido detectada diferença significativa na interação entre o tratamento de alagamento e o tempo de exposição a essa condição, é possível que o menor teor de $\mathrm{N}$ nos tecidos das plantas

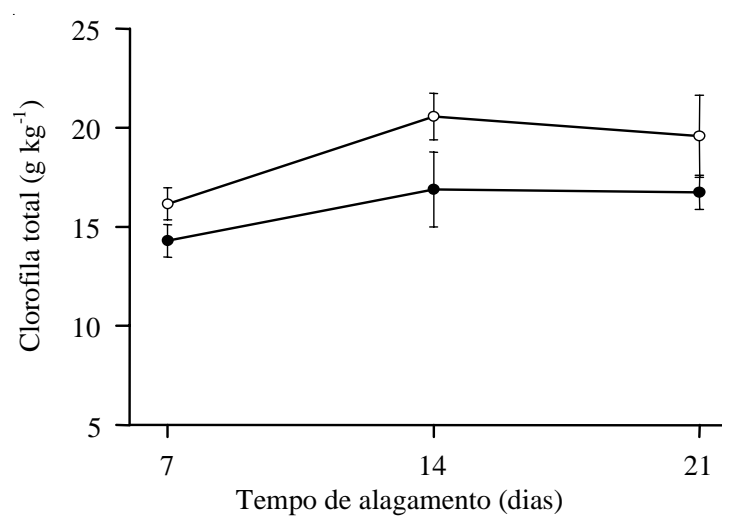

Figura 2. Teores de clorofila total nas folhas de plantas alagadas (•) e não-alagadas (0) de pupunheira aos 7, $14 \mathrm{e}$ 21 dias. As barras de erro representam o erro-padrão da média $(n=4)$. alagadas tenha contribuído para o estabelecimento da diferença nos teores de clorofila citados anteriormente.

Os teores de $\mathrm{P}$ nos tecidos das folhas não mostraram diferenças significativas entre os dois tratamentos e nem na interação tratamento x tempo.

$\mathrm{O}$ tratamento de alagamento provocou nítida redução dos teores de $\mathrm{K}$ foliar, tendo sido encontradas diferenças significativas entre os tratamentos $\left(\mathrm{F}_{1,15}=72,143 ; \mathrm{P}<0,001\right)$ e para a interação tratamento $x$ tempo $\left(\mathrm{F}_{2,15}=3,927 ; \mathrm{P}=0,043\right)$.

A deficiência de nutrientes provocada pelo alagamento das raízes pode ser atribuída a fatores tais como o acúmulo de substâncias tóxicas nas raízes, as quais inibem a absorção dos nutrientes minerais e causam decréscimo da disponibilidade destes elementos no solo. Tal modificação pode ser decorrência de alterações do estado de oxidação e mudanças de pH, inibição dos mecanismos de absorção, em virtude de uma baixa carga energética nas membranas, ou, ainda, da própria redução da superfície de absorção causada pela morte de raízes e perda de biomassa do sistema radicular (Drew \& Sisworo, 1979; Drew, 1991, 1997). Os dados de biomassa de raízes das plantas estudadas mostram que houve uma nítida redução nas plantas que tiveram suas raízes sob anoxia por 21 dias (Figura 3), o que explica parcialmente a redução na absorção de nutrientes.

A respiração anaeróbica é muito menos eficiente do que a aeróbica na produção de ATP por molécula de glicose utilizada, sendo, por isso, necessárias grandes quantidades de açúcares nos tecidos das raízes, para que possa ser gerado ATP suficiente para manter as células funcionando em condições anóxicas (Vartapetian, 1991; Vartapetian \& Jackson, 1997). O alagamento reduz a condutância estomática e provoca clorose nas folhas, diminuindo, portanto, a aqui-

Tabela 2. Teores de $\mathrm{N}$ orgânico, $\mathrm{P}$ e K, em $\mathrm{g} \mathrm{kg}^{-1}$ de matéria seca, nas folhas de plantas alagadas e não-alagadas de pupunheira aos 7, 14 e 21 dias $^{(1)}$.

\begin{tabular}{|c|c|c|c|c|c|c|}
\hline \multirow[t]{2}{*}{ Nutriente } & \multicolumn{3}{|c|}{ Alagadas } & \multicolumn{3}{|c|}{ Não-alagadas } \\
\hline & 7 & 14 & 21 & 7 & 14 & 21 \\
\hline $\mathrm{N}$ & $13,02 \pm 0,41$ & $15,63 \pm 0,55$ & $14,84 \pm 0,29$ & $18,48 \pm 1,14$ & $17,74 \pm 0,75$ & $16,67 \pm 0,72$ \\
\hline $\mathrm{P}$ & $0,44 \pm 0,08$ & $0,31 \pm 0,01$ & $0,30 \pm 0,02$ & $0,39 \pm 0,02$ & $0,39 \pm 0,01$ & $0,36 \pm 0,01$ \\
\hline K & $12,54 \pm 0,32$ & $10,20 \pm 0,54$ & $10,27 \pm 0,53$ & $14,81 \pm 0,98$ & $15,57 \pm 0,82$ & $15,38 \pm 0,61$ \\
\hline
\end{tabular}

(1)Os dados representam médias de 4 repetições. 
sição de carbono por meio da fotossíntese. Por outro lado, a translocação de açúcares solúveis das folhas para as raízes é bastante afetada pelo alagamento, e é drasticamente reduzida em numerosas espécies não-tolerantes (Kozlowski \& Pallardy, 1984; Pezeshki, 1994; Kozlowski, 1997). Deste modo, os açúcares solúveis produzidos na fotossíntese tendem a se acumular nas folhas, e não são translocados para as raízes, onde são necessários para manter a via glicolítica em funcionamento. Portanto, a maior disponibilidade de substrato respiratório, como a glucose, pode ser determinante na sobrevivência dos tecidos das raízes em ambientes anóxicos (Crawford \& Braendle, 1996; Drew, 1997; Vartapetian \& Jackson, 1997).

O tratamento de anoxia induziu o aumento dos teores de açúcares solúveis nas folhas, bulbos e raízes (Tabela 3). O aumento do teor de açúcares nos tecidos das folhas $\left(\mathrm{F}_{1,15}=24,829 ; \mathrm{P}<0,001\right)$ pode ser atribuído à diminuição na translocação, ou mesmo

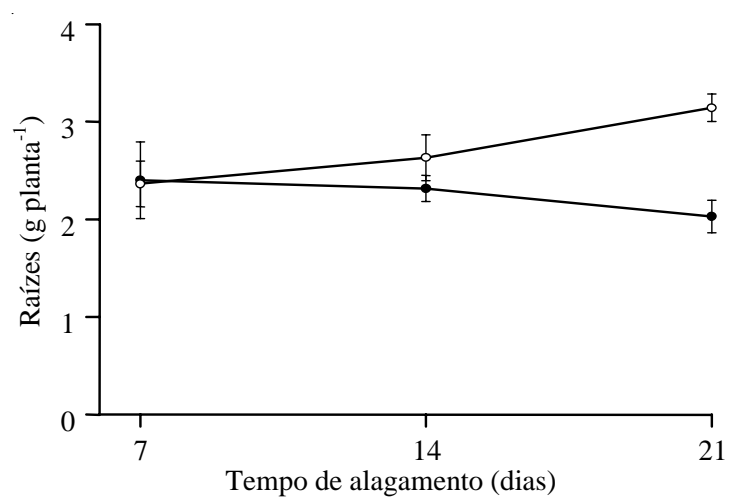

Figura 3. Massa dos sistemas radiculares de plantas alagadas (•) e não-alagadas (0) de pupunheira, aos 7, 14 e 21 dias. As barras de erro representam o erro-padrão da média $(n=4)$. redução do seu uso no crescimento. Porém, o grande aumento observado nos tecidos do bulbo $\left(F_{1,15}=36,098 ; \mathrm{P}<0,001\right)$ e raízes $\left(\mathrm{F}_{1,15}=143,389\right.$; $\mathrm{P}<0,001)$ das plantas alagadas deve ter sido originado da hidrólise de açúcares de reserva complexos como o amido. Com o prolongamento do tempo de anoxia, os teores de açúcares solúveis dos tecidos do bulbo e das raízes apresentaram tendência a aumentar até o período de 21 dias quando foi encerrado o experimento, e houve, no caso das raízes, uma interação significativa entre o tempo e o tratamento de anoxia $\left(F_{2,15}=5,226 ; P=0,019\right)$. Embora exista substrato disponível para a glicólise nas raízes e grande suprimento de açúcares potencialmente translocáveis a partir do bulbo, a sobrevivência das palmeiras poderá ter duração limitada, haja vista o declínio do sistema radicular e as deficiências nutricionais mostradas anteriormente.

Outro fato a ser considerado é o de que o grande aumento de açúcares solúveis observado nos tecidos do bulbo pode ter sido causado por anoxia, resultante do encharcamento dos tecidos e da constituição maciça deste órgão, que nas palmeiras encerra o meristema apical, o qual é uma região de intensa atividade respiratória e de grande demanda energética, necessitando, portanto, de um suprimento adequado de oxigênio. Apesar de sua grande quantidade de carboidratos de reserva, a espessura dos tecidos do bulbo dificulta a difusão do oxigênio até seu interior, tornando as áreas internas mais susceptíveis a condições de hipoxia, ou mesmo anoxia, caso existam barreiras adicionais à difusão do $\mathrm{O}_{2}$, tais como a submersão mesmo parcial dos tecidos.

A utilização anaeróbica dos açúcares traz como conseqüência o acúmulo de produtos tóxicos, tais como o etanol. Nas espécies sensíveis, o acúmulo

Tabela 3. Teores de açúcares solúveis, em $\mathrm{g} \mathrm{kg}^{-1}$ de matéria seca, nos tecidos de folhas, bulbos e raízes de plantas alagadas e não-alagadas de pupunheira aos 7,14 e 21 dias ${ }^{(1)}$.

\begin{tabular}{|c|c|c|c|c|c|c|}
\hline \multirow[t]{2}{*}{ Parte da planta } & \multicolumn{3}{|c|}{ Alagadas } & \multicolumn{3}{|c|}{ Não-alagadas } \\
\hline & 7 & 14 & 21 & 7 & 14 & 21 \\
\hline Folha & $128,2 \pm 2,0$ & $118,0 \pm 6,4$ & $115,4 \pm 5,2$ & $102,7 \pm 5,8$ & $106,5 \pm 1,7$ & $96,8 \pm 2,1$ \\
\hline Bulbo & $126,2 \pm 23,5$ & $132,6 \pm 6,8$ & $159,6 \pm 18,0$ & $64,1 \pm 7,2$ & $66,9 \pm 6,2$ & $82,1 \pm 5,7$ \\
\hline Raiz & $48,4 \pm 2,2$ & $82,2 \pm 6,6$ & $77,7 \pm 2,6$ & $25,1 \pm 4,1$ & $36,3 \pm 1,4$ & $44,3 \pm 3,1$ \\
\hline
\end{tabular}

(1)Os dados representam médias de 4 repetições. 
de etanol pode causar morte das células das raízes, sendo, portanto, necessário o desenvolvimento de mecanismos para sua eliminação, os quais podem incluir migração deste composto dos tecidos anóxicos para tecidos bem oxigenados, difusão para áreas vizinhas, ou, ainda, reorientando compostos glicolíticos intermediários para a formação de produtos finais, tais como malato, succinato, lactato, alanina, ácido aspártico, ácido glutâmico, serina e prolina (Crawford \& Zochowski, 1984; Pezeshki, 1994; Ricard et al., 1994).

Na pupunheira, assim como na maioria das palmeiras, o meristema radicular situa-se em uma posição que o torna susceptível de sofrer hipoxia pelo alagamento, haja vista que ele fica ligeiramente abaixo da superfície do solo. Por sua vez, em palmeiras jovens como as usadas no presente trabalho, o meristema apical situa-se imediatamente acima do meristema radicular, ou seja, próximo ao solo, sendo passível de sofrer o mesmo estresse com o encharcamento. Ambas as regiões citadas apresentam grande atividade metabólica e prioridade nos sistemas de proteção que visam a sobrevivência da planta (meristemas). A grande disponibilização de açúcares solúveis, para a glicólise no bulbo das plantas submetidas ao alagamento, sugere uma atividade glicolítica acentuada, e, por se tratar de estruturas constituídas de tecidos maciços, é possível que isto resulte em um acúmulo de substâncias tóxicas, tais como o etanol e outros, em face da dificuldade de difusão destes produtos para o meio externo ou outras regiões da planta.

Por ter sobrevivido a um período de 21 dias de alagamento contínuo, a pupunheira mostrou certa tolerância quando comparada com outras espécies lenhosas (Kozlowski, 1997). Porém, o aumento do tempo de estresse e as condições de óxido-redução do solo podem influenciar nesta tolerância e no comportamento pós-anóxico, por causa do desequilíbrio de macro e micronutrientes, como o Fe e $\mathrm{Mn}$ (Ponnamperuma, 1972), que são conhecidos ativadores de enzimas degenerativas. De toda maneira, foi claramente mostrado que o encharcamento do solo causa várias alterações metabólicas que resultam na redução imediata do crescimento e desenvolvimento das pupunheiras.

\section{Conclusões}

1. Plantas de pupunheira são afetadas pelo encharcamento do solo.

2. A condutância estomática e o teor de clorofila total são reduzidos antes de aparecerem sinais externos de clorose das folhas.

3. O encharcamento do solo reduziu a absorção de $\mathrm{N}$ e K, não tendo efeito significativo na absorção de fósforo.

4. A condição de encharcamento das raízes induz o aumento de açúcares solúveis nos tecidos das folhas e principalmente no bulbo e nas raízes.

\section{Referências}

ARNON, D. I. Copper enzymes in isolated chloroplasts: Polyphenoloxidase in Beta vulgaris. Plant Physiology, Rockville, v. 24, n. 1, p. 1-15, 1949.

ASHWELL, G. Colorimetric analysis of sugars. New York: Academic, 1957. p. 73-105. (Methods in enzymology, 3).

BOLLE-JONES E. W. Variations of chlorophyll and soluble sugar in oil palm leaves in relation to position, time of day and yield. Oleagineux, Montpellier, v. 23, n. 8/9, p. 505-511, 1968.

CHEN JUNIOR, P. S.; TORIBARA, T. Y.; WARNER, H. Microdetermination of phosphorus. Analytical Chemistry, Washington, v. 28, p. 1756-1758, 1956.

CRAWFORD, R. M. M.; BRAENDLE, R. Oxygen deprivation stress in a changing environment. Journal of Experimental Botany, Oxford, v. 47, n. 295, p. 145-159, 1996.

CRAWFORD, R. M. M.; ZOCHOWSKI, Z. M. Tolerance of anoxia and ethanol toxicity in chickpea seedlings (Cicer arietinum L.). Journal of Experimental Botany, Oxford, v. 35, n. 159, p. 1472-1480, 1984.

DREW, M. C. Oxygen deficiency and root metabolism: injury and acclimation under hypoxia and anoxia. Annual Review of Plant Physiology and Plant Molecular Biology, Palo Alto, v. 48, p. 223-250, 1997.

DREW, M. C. Oxygen deficiency in the root environment and plant mineral nutrition. In: JACKSON, M. B.; DAVIS, D. D.; LAMBERS, H. (Ed.). Plant life under oxygen deprivation: ecology, physiology and biochemistry. The Hague: SPB Academic, 1991. p. 303-316.

DREW, M. C.; SISWORO, E. J. The development of waterlogging damage in young barley plants in relation to 
plant nutrition status and changes in soil properties. New Phytologist, Cambridge, Inglaterra, v. 82, p. 301-314, 1979.

KOZLOWSKI, T. T. Responses of woody plants to flooding and salinity. Tree Physiology Monograph, Victoria, n. 1, p. 1-29, 1997.

KOZLOWSKI, T. T.; PALLARDY, S. G. Effect of flooding on water, carbohydrate, and mineral relations. In: KOZLOWSKI, T. T. (Ed.). Flooding and plant growth. Orlando: Academic, 1984. p. 165-193.

McCREADY, R. M.; GUGGOLZ, J.; SILVIERA, V.; OWENS, H. S. Determination of starch and amylose in vegetables: application to peas. Analytical Chemistry, Washington, v. 22, n. 9, p. 1156-1158, 1950.

PEZESHKI, S. R. Plant response to flooding. In: WILKINSON, R. E. (Ed.). Plant-environment interactions. New York: M. Dekker, 1994. p. 289-321.

PEZESHKI, S. R.; PARDUE, J. H.; DELAUNE, R. D. Leaf gas exchange and growth of flood-tolerant and floodsensitive tree species under low soil redox conditions. Tree Physiology, Victoria, v. 16, p. 453-458, 1996.

PONNAMPERUMA, F. N. The chemistry of submerged soils. Advances in Agronomy, San Diego, v. 24, p. 29-96, 1972.
RICARD, B.; COUÉE, I.; RAYMOND, P.; SAGLIO, P. H.; SAINT-GES, V.; PRADET, A. Plant metabolism under hypoxia and anoxia. Plant Physiology and Biochemistry, Paris, v. 32, n. 1, p. 1-10, 1994.

SOLORZANO, L. Determination of ammonia in natural waters by the phenol hypoclorite method. Limnology and Oceanography, Seattle, v. 14, p. 799-801, 1969.

VARTAPETIAN, B. B. Flood-sensitive plants under primary and secondary anoxia: ultrastructural and metabolic responses. In: JACKSON, M. B.; DAVIS, D. D.; LAMBERS, H. (Ed.). Plant life under oxygen deprivation: ecology, physiology and biochemistry. The Hague: SPB Academic, 1991. p. 201-216.

VARTAPETIAN, B. B.; JACKSON, M. B. Plant adaptations to anaerobic stress. Annals of Botany, London, v. 79, p. 3-20, 1997. Supplement A.

VILLACHICA, H.; CARVALHO, J. E. U.; MULLER, C. H.; DIAZ, S. C.; ALMANZA, M. Frutales y hortalizas promisorios de la Amazonia. Lima: Tratado de Cooperación Amazónica, 1996. 367 p.

WEATHERLEY, P. E. Studies in the water relations of the cotton plant I: the field measurements of water deficits in leaves. New Phytologist, Cambridge, Inglaterra, v. 49, p. 81-97, 1950. 